Journal of Clinical Investigation

Vol. 42, No. 12,1963

\title{
PATTERNS OF PRESSOR RESPONSE TO NOXIOUS STIMULI IN NORMAL, HYPERTENSIVE, $\Lambda$ ND DIABETIC SUBJECTS*
}

\author{
By ALVIN P. SHAPIRO, SPERO E. MOUTSOS, AND EMANUEL KRIFCHER \\ (From the Department of Medicine, University of Pittsburgh School of Medicine, \\ Pittsburgh, Pa.)
}

(Submitted for publication April 30, 1963; accepted August 16, 1963)

In earlier studies, the influence of various "host factors" affecting the pressor responses to noxious stimuli in hypertensive and normotensive subjects was investigated. Information was obtained indicating that intrinsic factors predominate in determining the type and severity of such pressor responses (1). It also was demonstrated that lowering basal blood pressure in the hypertensive patient with therapeutic doses of reserpine and chlorothiazide did not decrease these responses (2).

The present studies represent a continuing effort to define the factors determining patterns of pressor response to noxious stimuli, with particular attention to the physiologic mechanisms that mediate these responses. As in previous studies, the cold pressor test was assumed to measure the neurogenic component, and this response was compared to the results with two operationally simple psychological stimuli $(1,2)$. Synthetic angiotensin II, presently the most potent peripheral vasoconstrictor known, was used in this experiment as a direct humoral vasoconstrictor and was administered as a single intravenous dose, in a constant amount and with a constant technique. An automatic indirect blood pressure recorder that permits an objective recording, obviates the necessity of arterial cannulation, and allows the testing of many subjects with minimal inconvenience to them was employed. In addition to normotensive and hypertensive patients, the present study utilized diabetic subjects, a population with a tendency to neurologic abnormalities that theoretically should affect their pathways of blood pressure responsiveness.

* Supported by training (HTS 5467) and research (HE-05711) grants from the U. S. Public Health Service and by the Health Research and Services Foundation of the United Fund of Allegheny County, $\mathrm{Pa}$.

\section{MATERIALS AND METHODS}

A total of 113 subjects in four groups were studied: 55 were hypertensive (diastolic pressure, $90 \mathrm{~mm} \mathrm{Hg}$ or above without obvious primary renal or endocrine disease as its cause), and 58 were normotensive. All were patients in either the Presbyterian-University Hospital or the Falk Outpatient Clinic of the University of Pittsburgh School of Medicine. Twenty of the hypertensive subjects were diabetic as were 25 of the normotensives. Criteria for the presence of diabetes consisted of the demonstration of an elevated fasting blood sugar, an abnormal glucose tolerance curve, or both; many subjects had evidence of other diabetic concomitants consisting of microaneurysms, neuropathy, or nephropathy. The normotensive nondiabetic controls consisted of patients with diseases not involving the cardiovascular or renal systems. The salient clinical features in the four groups are indicated in Table $I$. The small differences in ages between the two normotensive groups and the two hypertensive groups were not significant statistically. A slightly higher basal blood pressure was present in the normotensive diabetics as compared to the nondiabetic normotensive group; between the two hypertensive groups, the diabetics had slightly lower basal blood pressure ( $p=.05$ for each).

Subjects were included as they became available to the investigators during the course of the study. None were chosen who were receiving therapeutic agents known or suspected to affect autonomic nervous system reactivity. These included all hypotensive drugs, ${ }^{1}$ steroids, tranquilizers, sedatives, analgesics, and psychic energizers. $\mathrm{Pa}$ tients who could not cooperate for various reasons, were too ill to undergo the tests, or had priority needs for therapy were not included. Consequently, the groups that were studied cannot be considered random samples of the various populations under consideration. Despite the lack of a systematic technique of sampling, however, which often is impractical in this type of investigation, the clinical characteristics of the subjects indicated the inclusion of the usual range of manifestations of these diseases.

Patients were studied usually in the morning, in the

${ }^{1}$ A few hypertensive subjects regularly taking thiazides were included although they were not given the drug on the test day. Our previous studies have indicated that thiazides do not affect the pressor responses to these stimuli (2). 
TABLE I

Clinical data

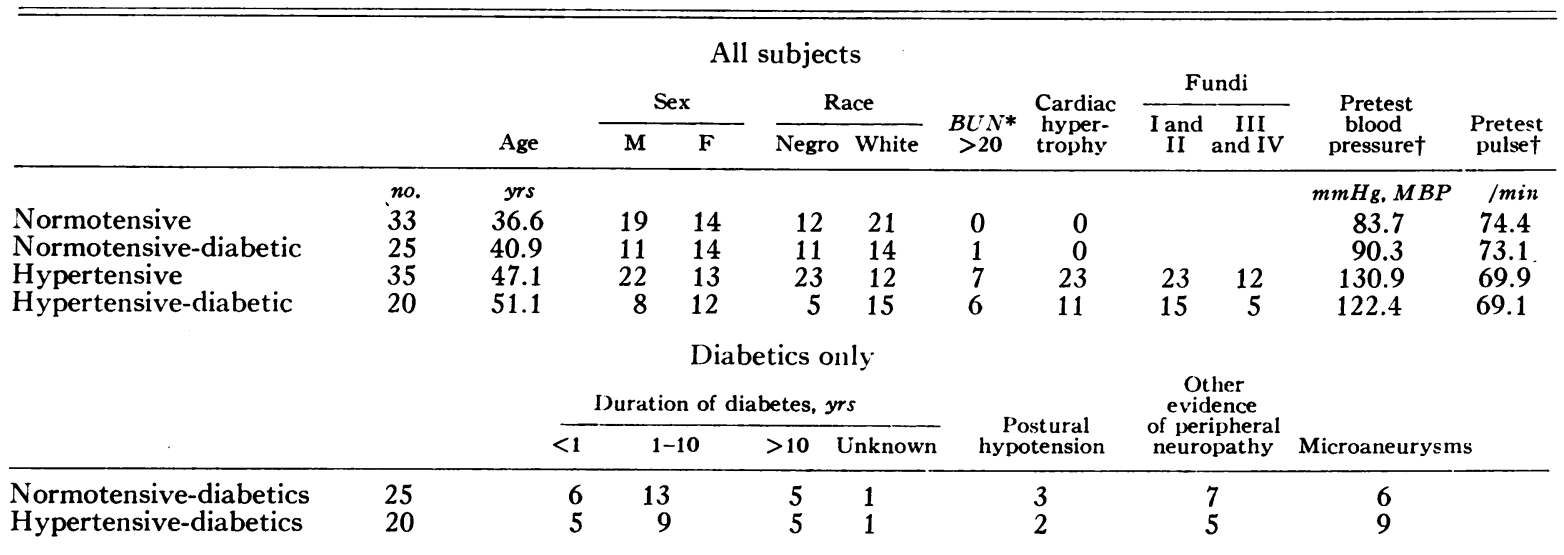

* Blood urea nitrogen.

$\dagger$ Average of base lines before all four noxious stimuli. No significant differences among the four base lines for each group. $\mathrm{MBP}=$ mean blood pressure.

fasting state. In a few instances, tests were done in the afternoon, with the patient omitting lunch. Insulin or oral hypoglycemic drugs were omitted on the day of testing in those diabetics receiving these agents. Blood pressure was determined indirectly with the Gilford automatic blood pressure recorder; a cardiotachometer, operating from a photoelectric pickup attached to the ear lobe, recorded pulse rate with each blood pressure cycle (1).

Patients were put to bed in a quiet room. After attachment of the apparatus they rested, alone in the room, for 15 to 30 minutes while blood pressure and pulse measurements were made automatically at 1 -minute intervals. After the rest period, four stimuli were administered at 15 - to 30 -minute intervals; between tests, the investigator again left the room. Three of the stimuli have been described previously (1):1) venipuncture and the intravenous injection of $10 \mathrm{ml}$ of normal saline with a stylized protocol during which the subject is asked to "count backwards from 100 as rapidly as possible" ("saline" test) ; 2) a standard cold pressor test; and 3 ) the rapid reading of a chart containing the names of colors, printed in colors other than the color name itself ("color" test). The fourth stimulus consisted of the intravenous injection, over a period of 1 minute, of $0.03 \mu \mathrm{g}$ per $\mathrm{kg}$ of angiotensin II ${ }^{2}$ (to a maximal dose of $2.5 \mu \mathrm{g}$ in patients weighing over $83 \mathrm{~kg}$ ) prepared in a concentration of $0.25 \mu \mathrm{g}$ per $\mathrm{ml}$. After administration of the angiotensin, blood pressures were taken as closely as possible to every 30 seconds by cycling the machine manually. The maximal systolic and diastolic rises generally occurred from $1 \frac{1}{2}$ to $2 \frac{1}{2}$ minutes after the start of the injection. The maximal change in pulse rate, which usually was downward, also was recorded during this period.

The four stimuli were not administered randomly, but

2 As synthetic valyl-5-angiotensin II, supplied by Ciba Pharmaceutical Co., Summit, N. J. in the same order for all subjects, as follows: test 1 , saline; test 2 , cold pressor; test 3 , angiotensin; test 4 , color. The response for each test represented the difference between the maximal change and the average of four readings immediately before the particular stimulus. Thus, a new base line was used for each test, but statistical analyses indicated no significant differences among these four base lines in any of the four groups of patients. The systolic and diastolic responses were converted to a single figure, the calculated mean blood pressure [diastolic + (pulse pressure/3)], to simplify later computations. Separate analyses of the systolic and diastolic components of the responses were not performed, since it was not felt that these would add significantly to the interpretation of the data in this study. It was observed, however, that angiotensin produced primarily a diastolic response, while the cold pressor, saline, and color tests varied from a predominantly diastolic elevation, through a "mixed" response, to a predominantly systolic elevation, respectively, as in previous studies $(1,2)$. The average response, in both mean blood pressure and pulse rate, was calculated for each of the four groups, and compared for each test by analysis of variance (3).

The Clyde Mood Scale, a self-administered, adjectiverating, psychological test, was used with most of the subjects at the conclusion of the experimental period. This test provides an estimate of the patient's attitudes at the time of testing. The calculated scores deviate from a norm of 50 and estimate the mood of the subject in six categories, i.e., friendly, energetic, clear-thinking, aggressive, jittery, depressed (1).

\section{RESULTS}

The average response to all four stimuli and the statistical analyses are presented in Table II. 
TABLE II

Blood pressure and pulse responses

\begin{tabular}{|c|c|c|c|c|c|c|c|c|}
\hline \multirow[b]{2}{*}{ Group } & \multicolumn{4}{|c|}{ Blood pressure response } & \multicolumn{4}{|c|}{ Pulse rate response } \\
\hline & $\begin{array}{l}\text { Angio- } \\
\text { tensin }\end{array}$ & $\begin{array}{c}\text { Cold } \\
\text { pressor }\end{array}$ & Saline & Color & $\begin{array}{l}\text { Angio- } \\
\text { tensin }\end{array}$ & $\begin{array}{c}\text { Cold } \\
\text { pressor }\end{array}$ & Saline & Color \\
\hline & \multicolumn{4}{|c|}{$m m \mathrm{Hg}$, mean $B P$} & \multicolumn{4}{|c|}{ beats/minute } \\
\hline $\begin{array}{l}\text { Normotensive } \\
\text { Normotensive-diabetic } \\
\text { Hypertensive } \\
\text { Hypertensive-diabetic }\end{array}$ & $\begin{array}{l}26.2 \\
35.5 \\
39.6 \\
45.4\end{array}$ & $\begin{array}{l}19.6 \\
16.1 \\
30.1 \\
18.6\end{array}$ & $\begin{array}{r}9.4 \\
12.7 \\
19.3 \\
14.5\end{array}$ & $\begin{array}{r}8.1 \\
10.1 \\
15.0 \\
11.2\end{array}$ & $\begin{array}{l}-8.3 \\
-9.5 \\
-4.9 \\
-0.9\end{array}$ & $\begin{array}{r}10.0 \\
6.4 \\
9.6 \\
7.6\end{array}$ & $\begin{array}{r}10.1 \\
11.3 \\
14.3 \\
8.1\end{array}$ & $\begin{array}{r}8.3 \\
10.1 \\
10.0 \\
6.3\end{array}$ \\
\hline $\begin{array}{ll}\text { Among all groups } & \mathrm{F} \\
\mathrm{p}\end{array}$ & $\begin{array}{l}17.52 \\
<.001^{*}\end{array}$ & $\begin{array}{l}9.59 \\
.001 *\end{array}$ & $\begin{array}{l}3.57 \\
.025^{*}\end{array}$ & $\begin{array}{l}3.89 \\
.01 *\end{array}$ & $\begin{array}{l}7.08 \\
<.01 *\end{array}$ & $\begin{array}{r}1.36 \\
>.05\end{array}$ & $\begin{array}{l}3.42 \\
.025^{*}\end{array}$ & $\begin{array}{r}1.26 \\
>.05\end{array}$ \\
\hline \multicolumn{9}{|c|}{$p$ values for group comparisons } \\
\hline $\begin{array}{l}\mathrm{N} \times \mathrm{N}-\mathrm{D} \dagger \\
\mathrm{N} \times \mathrm{H} \\
\mathrm{N}-\mathrm{D} \times \mathrm{H}-\mathrm{D} \\
\mathrm{H} \times \mathrm{H}-\mathrm{D}\end{array}$ & $\begin{array}{c}.001^{*} \\
.01-.001^{*} \\
.001^{*}\end{array}$ & $\begin{array}{l}>.05 \\
<.001^{*} \\
>.05 \\
.001^{*}\end{array}$ & $\begin{array}{l}>.05 \\
<.001 * \\
>.05 \\
>.05\end{array}$ & $\begin{array}{l}>.05 \\
.01-.001 * \\
>.05 \\
>.05\end{array}$ & $\begin{array}{l}>.05 \\
>.05 \\
<.001^{*} \\
.02^{*}\end{array}$ & & $\begin{array}{l}>.05 \\
.02^{*} \\
>.05 \\
.01^{*}\end{array}$ & \\
\hline
\end{tabular}

* Significant values $(\mathrm{p}=.05$ or less)

$\dagger \mathrm{N}=$ normotensive; $\mathrm{N}-\mathrm{D}=$ normotensive-diabetic; $\mathrm{H}=$ hypertensive $; \mathrm{H}-\mathrm{D}=$ hypertensive-diabetic.

These responses are depicted in Figure 1. As shown in previous studies, the nondiabetic hypertensives $(\mathrm{H})$ were significantly more reactive than normal subjects $(\mathrm{N})$ to both of the psychological stimuli and to the cold pressor test. In addition, this study demonstrated that they reacted more vigorously to angiotensin. The diabetic hypertensives (H-D) similarly were more reactive to angiotensin than normotensive diabetics (N-D) and seemingly more responsive to the cold pressor, saline, and color tests, although the differences with these latter three tests were not significant statistically.

Striking contrasts were evident between the diabetics and nondiabetics, both hypertensive and normotensive. The diabetics were more respon-

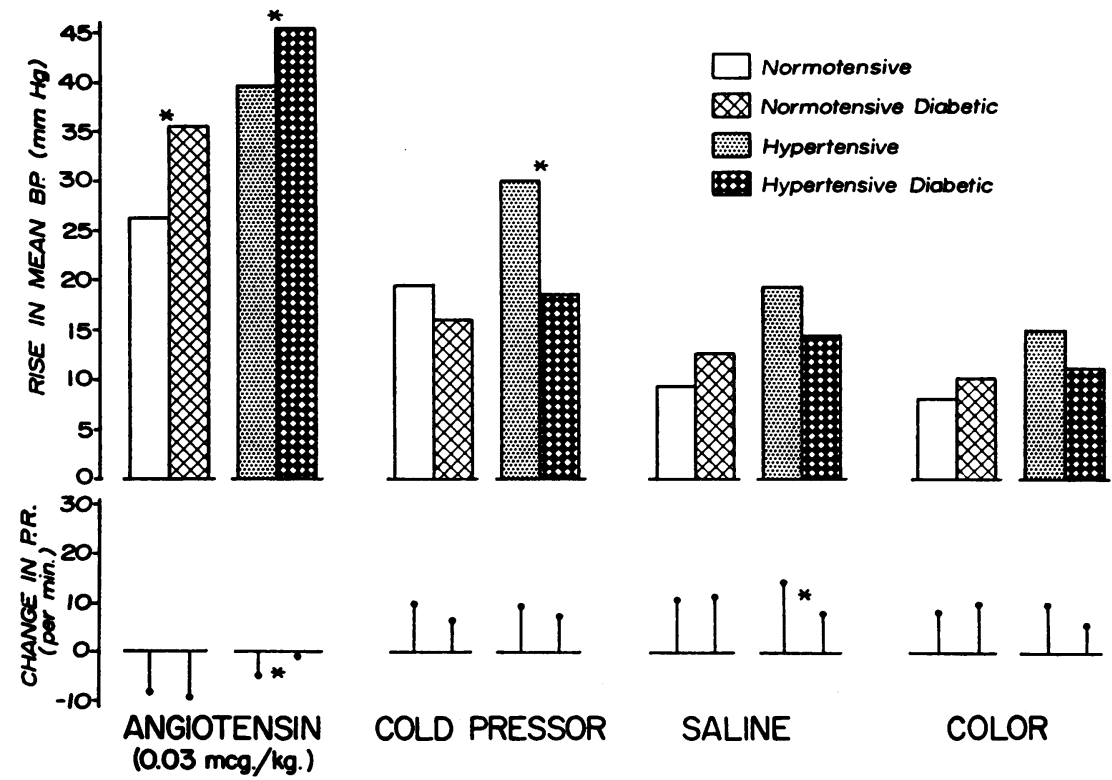

Fig. 1. Blood PRESSURe AND PULSE RATE RESPONSES to FOUR DIFFERENT NOXIOUS STIMULI IN THE FOUR GROUPS OF PATIENTS INDICATED. The data are arranged in the figure to show the contrast between diabetic and nondiabetic groups. Significant differences $(p<.0 .5)$ are indicated by an asterisk. Further statistical comparisons, namely, of normotensives vs. hypertensives, are indicated in Table II. 
sive to angiotensin and less reactive to the cold pressor stimulus. These changes were highly significant with the exception of that between the cold pressor responses in N and N-D (19.6 and $16.1 \mathrm{~mm} \mathrm{Hg}$, respectively, $\mathrm{p}>.05$ ). The average differences between angiotensin (A) and cold pressor $(\mathrm{CP})$ responses, however, were markedly increased in the diabetics $(\mathrm{H}=9.5 \mathrm{~mm} \mathrm{Hg}, \mathrm{H}-\mathrm{D}$ $=26.7 \mathrm{~mm} \mathrm{Hg}, \mathrm{p}<.001 ; \mathrm{N}=6.6 \mathrm{~mm} \mathrm{Hg}, \mathrm{N}-\mathrm{D}$ $=19.4 \mathrm{~mm} \mathrm{Hg}, \mathrm{p}=.01>.001)$. This was emphasized further when the ratio $\mathrm{A} / \mathrm{CP}$ was determined. The median values of $\mathrm{A} / \mathrm{CP}$ were higher for the diabetics $(H=1.30 ; H-D=2.62$; $\mathrm{N}=1.26 ; \mathrm{N}-\mathrm{D}=2.57)$. The percentages of subjects with $\mathrm{A} / \mathrm{CP}$ values of 2.0 or above (Figure 2 ) were significantly greater (chi square; $p<.01$ ) in each of the diabetic groups as compared to its respective nondiabetic group. ${ }^{3}$

3 The mean values of the pressor responses for the ten patients in the N-D group with postural hypotension, or other clinical evidence of peripheral neuropathy (impaired motor reflexes, grossly diminished vibratory sense, or impotence), or both, were $36.1,15.9,14.2$, and 11.6 $\mathrm{mm} \mathrm{Hg}$ to the angiotensin, cold pressor, saline, and color tests, respectively, with $71 \%$ having an $\mathrm{A} / \mathrm{CP}$ ratio greater than 2.0 ; these values were not significantly different from the remainder of the group. Similarly, for the seven patients in the $H-D$ group, the mean values were 47.8, 15.8, 12.1, and $11.9 \mathrm{~mm} \mathrm{Hg}$ to these four tests, with $70 \%$ having an $\mathrm{A} / \mathrm{CP}$ ratio greater than 2.0 , again not different from the rest of the group.

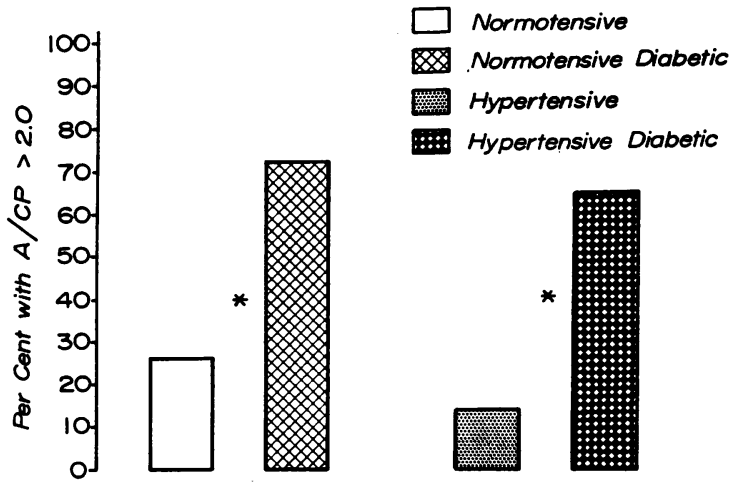

Fig. 2. Comparison of PERCENTAGe OF SUBJeCtS With ANGIOTENSIN/COLD PRESSOR (A/CP) RATIO GREATER THAN 2.0 IN THE DIABETIC AND NONDIABETIC GROUPS. Differences are significant $(p<.01)$ by chi square analysis as indicated by an asterisk.

Still further demonstration of the contrasting differences in the angiotensin and cold pressor responses in the diabetics and nondiabetics is provided by the frequency distribution curves set forth in Figures 3 and 4 . These demonstrate separate peaks for diabetics and nondiabetics, within both the normotensive (Figure 3 ) and the hypertensive (Figure 4) populations. Moreover, the peaks for the diabetics move in opposite directions on the curves for the two tests, i.e., to the left for the cold pressor and to the right for angiotensin.

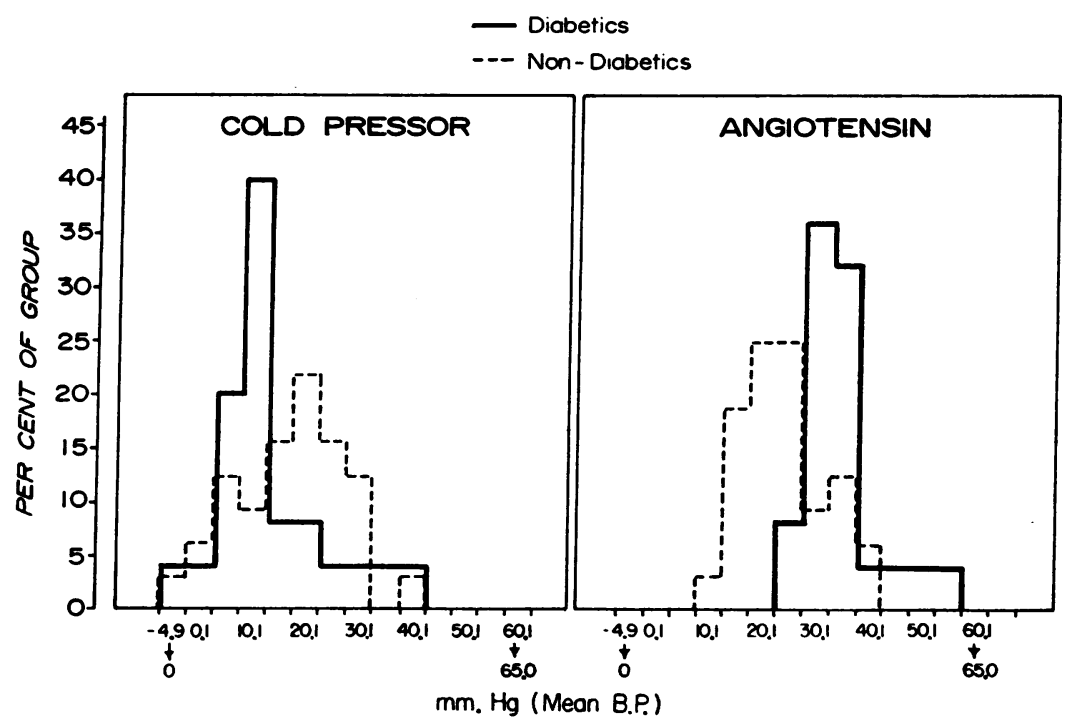

Fic. 3. FReQUeNCY Distribution OF PRESSOR RESPONSES IN NORMOTENSIVES TO ANGIOTENSIN AND COLD PRESSOR. 


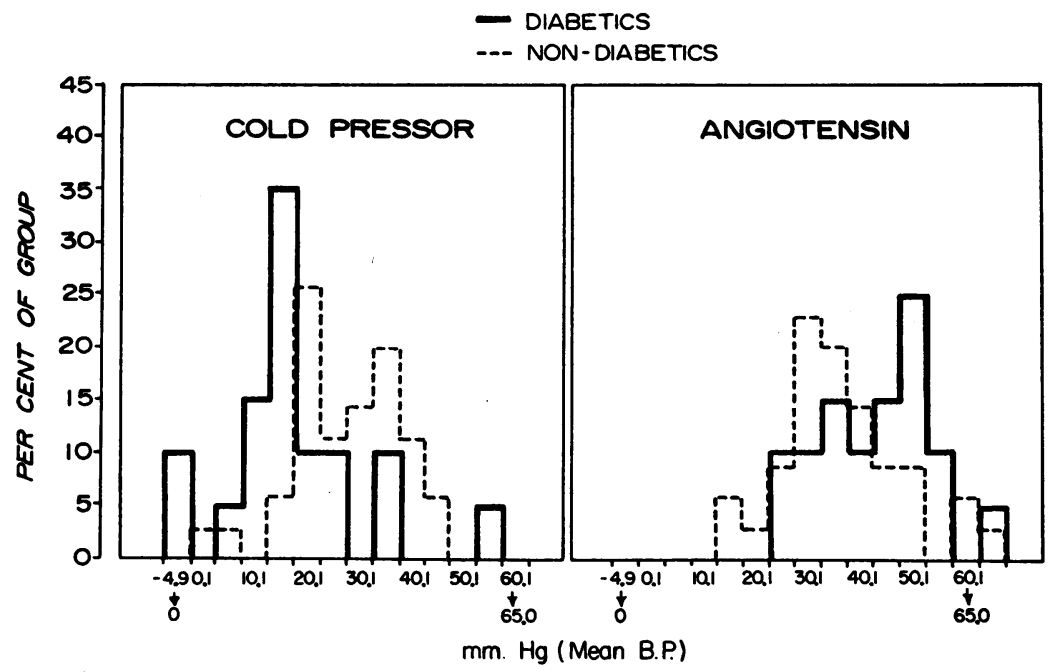

Fig. 4. FREQUENCY DISTRIBUTION OF PRESSOR RESPONSES IN HYPERTENSIVES TO ANGIOTENSIN AND COLD PRESSOR.

Comparison of the pattern of responses to the two psychological stimuli was noteworthy, since these responses did not decline significantly in the diabetics despite their decreased cold pressor reactivity. This is shown best in Figure 5, which demonstrates the percentile change in the re- sponses to each test in the H,N-D, and H-D groups with the responses in the normal group as the base lines. In the $\mathrm{H}$ group, all four responses were enhanced. In the two diabetic groups, N-D and H-D, the responses to the two psychological stimuli, like that to angiotensin, were

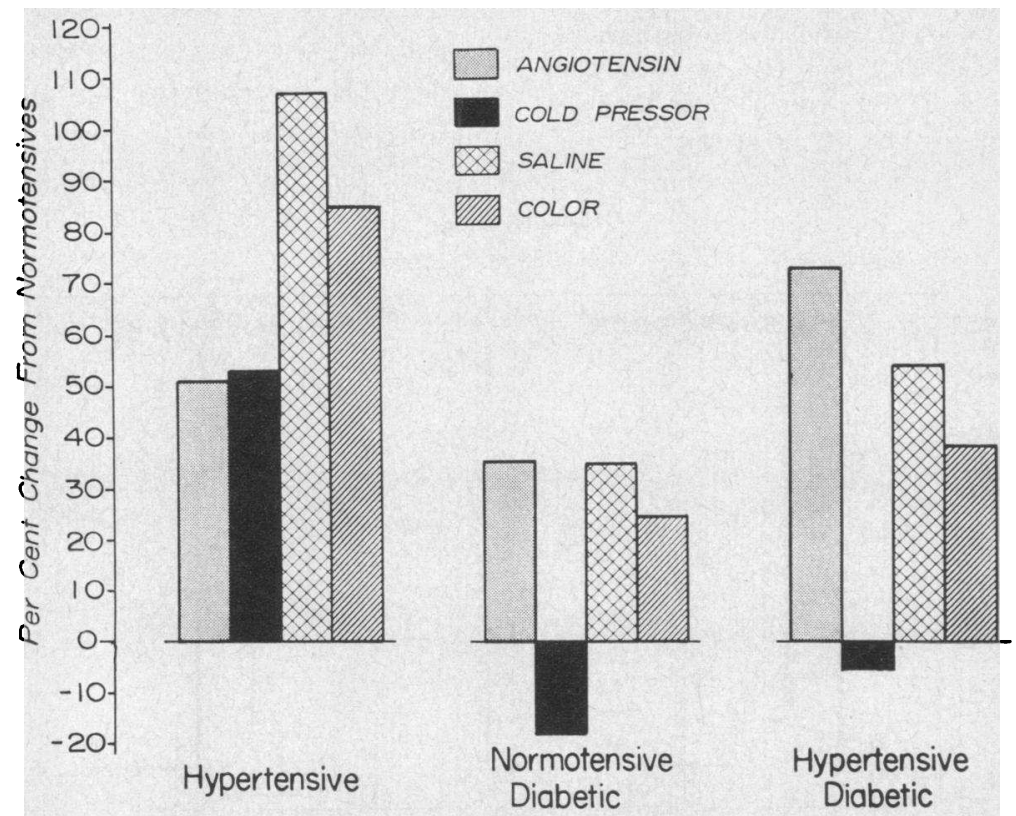

Fig. 5. COMPARISON OF THE PRESSOR RESPONSES IN THE THREE EXPERIMENTAL GROUPS TO THOSE IN THE NORMAL SUBjects. For each test, the pressor response ( $\mathrm{mm} \mathrm{Hg}$, mean blood pressure) in the experimental group has been expressed as the percentage of the response to the same test in the normotensive nondiabetic group. 
TABLE III

Clyde Mood Scale scores

\begin{tabular}{|c|c|c|c|c|c|c|}
\hline Group & Friendly & Energetic & Clear-thinking & Aggressive & Jittery & Depressed \\
\hline $\begin{array}{l}\text { Normotensive } \\
\text { Normotensive-diabetic } \\
\text { Hypertensive } \\
\text { Hypertensive-diabetic } \\
\qquad \text { F } \\
\text { p }\end{array}$ & $\begin{array}{l}53.0 \\
50.0 \\
50.4 \\
50.8 \\
0.56 \\
>.05\end{array}$ & $\begin{array}{c}46.5 \\
45.7 \\
47.5 \\
49.8 \\
0.50 \\
>.05\end{array}$ & $\begin{array}{c}46.0 \\
45.3 \\
46.8 \\
51.1 \\
1.23 \\
>.05\end{array}$ & $\begin{array}{c}44.8 \\
43.7 \\
44.5 \\
46.8 \\
0.41 \\
>.05\end{array}$ & $\begin{array}{r}51.0 \\
48.8 \\
52.3 \\
52.2 \\
0.91 \\
>.05\end{array}$ & $\begin{array}{l}49.4 \\
45.1 \\
50.2 \\
50.2 \\
2.30 \\
>.05\end{array}$ \\
\hline
\end{tabular}

increased, although the cold pressor reactivity was depressed.

The pulse responses showed little difference. The only meaning ful contrast was between $\mathrm{H}$ and $\mathrm{H}-\mathrm{D}$ in the decline that occurred after the administration of angiotensin. This decline was less in the $H-D$, perhaps indicating that impairment of the autonomic nervous system prevented the usual reflex fall in pulse rate to this predominantly diastolic rise in pressure. Similarly, the smaller rises to other stimuli in the H-D ( $\mathrm{p}=.01$ for the saline test) might represent impairment of cardioaccelerator mechanisms.

The Clyde Mood Scale scores (Table III) indicated no significant differences among the four groups in the various categories measured. Thus, insofar as this test is an adequate measure, the attitudes of the subjects in the four groups were fairly uniform.

\section{DISCUSSION}

The data confirm that hypertensive patients are more responsive than normotensive subjects to simple psychological stimuli as well as to the cold pressor test. In addition, the present study indicates that they also react more vigorously to the direct humoral vasopressor influence of angiotensin. The latter observation is interesting because of current controversy concerning the role of angiotensinase in determining the response to angiotensin. It has been demonstrated with angioten$\sin \mathrm{I}^{131}$ (4) and with rat bioassay (5) that the in vitro half-life of angiotensin in hypertensive plasma is shortened. Thus, increased destruction by an angiotensinase in the hypertensive subject has been suggested as an adaptive mechanism to chronic angiotensinemia. On the other hand, the in vivo half-life of angiotensin $\mathrm{I}^{131}$ appears to be prolonged in the hypertensive (6), and Wood's data from the offspring of hypertensive sub- jects indicate decreased angiotensin destruction in these individuals (7). Klaus, in fact, found no differences in angiotensinase activity of sera from normal and hypertensive subjects (8). The evidence from angiotensin $\mathrm{I}^{131}$ can be questioned, since data obtained with tritiated angioten$\sin$ (9) indicate that the fate of the iodinated compound may not reflect the true behavior of the polypeptide. In addition, Khairallah, Bumpus, Page, and Smeby (10) have demonstrated a number of nonspecific angiotensinases. Our present data would indicate at least that if angiotensinase levels are elevated in chronic hypertension, they do not inhibit the pressor response to an acute injection of the synthetic polypeptide. Kaplan and Silah have provided similar evidence of hyperreactivity to angiotensin in a group of essential hypertensives given a more chronic infusion of the material (11).

What appears evident is the importance of intrinsic responsiveness in evaluation of blood pressure control as demonstrated in the present study by hyperresponsiveness in the hypertensive subject to several pressor stimuli, presumably acting by different mechanisms. Gombos and associates (12) have pointed out that such an increased pressor response need not imply an increased sensitivity of arterioles per se, since the percentile rise in blood pressure in the hypertensives essentially was unchanged from the normal. Moreover, since peripheral resistance increases exponentially with decrease in the radius of the arteriole, a change in a vessel already narrowed produces a larger increase in peripheral resistance than the same change in a more dilated arteriole. The fact remains, however, that the clinically important measurement, namely, the actual blood pressure rise in millimeters of $\mathrm{Hg}$, is greater in the hypertensive subject. Moreover, we have shown that the response to these stimuli is not dependent on the 
base-line pressure in the hypertensive individual; among normotensives it is greater in those with a family history of hypertension (1). In addition, hypertensive subjects with basal blood pressures lowered by therapeutic doses of reserpine and chlorothiazide show no decrease in pressor response to noxious stimuli and, in fact, have an enhanced percentile rise (2).

In our previous studies, analysis of systolic, diastolic, and pulse rate relationships permitted suggestions concerning the proportional changes in peripheral resistance and cardiac output in the production of the pressor responses with the stimuli that we have employed (1). Without simultaneous cardiac output measurements, however, these provide only inferences for the understanding of the hemodynamic mechanisms involved and have not been attempted in the present study. Moreover, recent data that include the demonstration of high outputs with normal resistances in young hypertensives suggest that it may be more correct to conceive of hypertension hemodynamically as an imbalance between output and resistance rather than purely a disease of elevated resistance (13). Thus, a normal peripheral resistance that is unchanged with a rise in cardiac output becomes a comparatively high resistance. Such a concept adds importance to increased responsiveness as demonstrated solely by blood pressure measurement, independent of the relative contributions of output and resistance to the change.

The differences demonstrated between diabetics and nondiabetics, which are reflected in percentile rise as well as in millimeters of $\mathrm{Hg}$, can be interpreted in terms of a hypothesis that blood pressure responses are regulated by two independent yet interrelated mechanisms: 1) the neurogenic, mediated efferently by the sympathetic nervous system through its innervation of vascular structures and terminal release of norepinephrine and 2) the humoral, represented by clirect effects on arteriolar smooth muscle by circulating vasoconstrictor materials, among which may be polypepticles whose prototype is angiotensin II. The concept that the cold pressor response is mediated by efferents in the sympathetic nervous system, and accordingly. measures the neurogenic component, is supported by observations that it is reduced or blocked by spinal anesthesia (14) and by ganglion-blocking
(15) and sympatholytic drugs (16). Similarly, although some recent evidence suggests a contributing central action (17) and mediation through the sympathetic nervous system (18), angiotensin has been primarily established as a direct vasoconstrictor of arterioles (19).

Impairment of the circulatory response to the cold pressor test corresponds to previous demonstrations in diabetic subjects of failure of other circulatory adjustments mediated by the sympathetic nervous system (20). Enhanced responsiveness to humoral agents, e.g., exogenous circulating norepinephrine, has been demonstrated previously in diabetics $(21,22)$, and the present study indicates that this occurs with a different type of peripheral vasoconstrictor as well, namely, the polypeptide angiotensin. Increased reactivity to humoral materials is typical of denervated arterioles. Its presence in the diabetic after administration of angiotensin argues against any significant role of the autonomic nervous system in normally mediating responses to angiotensin.

The clinical manifestation of these two contrasting effects in the diabetics is the increase in the $\mathrm{A} / \mathrm{CP}$ ratio, which may indicate autonomic nervous system impairment. The ratio also is increased in hypertensive patients after administration of sympatholytic drugs (16). Although the $\mathrm{A} / \mathrm{CP}$ ratio was usually high, i.e., $>2.0$, in those diabetics with postural hypotension or other obvious evidence of peripheral neuropathy, it is of considerable interest that it was elevated as well in patients without clinical signs of neurological impairment including some with recent or even latent glucose intolerance. Whether a change in the regulation of blood pressure of this type might offer an additional guide to early diabetes detection poses a question that merits additional epidemiological study.

Brust and Ferris have discussed the evidence for a dual system of blood pressure regulation, neurogenic and humoral, in the organism (23), and Page has suggested that the humoral pathways are the more primitive (24). Variability of pathways of response to noxious stimuli of psychological origin also was proposed some years ago by Ferris, Reiser, Stead, and Brust (25), but "neurogenic" and "psychogenic" are still often considered synonymous. Further evidence to support a concept of flexibility of response is provided by 
the present data, which indicate the persistance of responses to the saline test, a procedure that includes both a venipuncture and mental arithmetic, and the color test in the diabetics, despite the decreased activity of the cold pressor or autonomic pathway.

\section{SUM MARY}

The blood pressure responses to four different noxious stimuli were studied in 113 normotensive and hypertensive patients. Subjects with and without diabetes were included in each category. Hypertensives were noted to be more reactive to angiotensin II as well as to the cold pressor test and to simple psychological stimuli. Diabetics displayed decreased reactivity to the cold pressor stimulus, but enhanced responses to angiotensin, as compared with nondiabetics; their responses to the psychological stimuli were not decreased significantly in spite of evidence of impairment of the cold pressor response. The results are discussed in terms of the pertinence of intrinsic responsiveness to pressor stimuli in evaluation of the renal pressor mechanism and the interrelationships between neurogenic and humoral pathways in blood pressure regulation.

\section{ACKNOWLEDGMENTS}

Mrs. Jean Small, Miss Jacqueline McArdle, and Miss Eileen Tyrrell provided valued technical assistance. The help of Dr. James Bonessi of the Diabetic Clinic of the Falk Outpatient Department in obtaining diabetic subjects for study is acknowledged. Support for hospitalization of several of the patients included in the study was from Clinical Research Center grant FR-56 from the U. S. Public Health Service.

\section{REFERENCES}

1. Shapiro, A. P. An experimental study of comparative responses of blood pressure to different noxious stimuli. J. chron. Dis. 1961, 13, 293.

2. Shapiro, A. P. Pressor responses to noxious stimuli in hypertensive patients. Effects of reserpine and chlorothiazide. Circulation 1962, 26, 242.

3. Edwards, A. L. Statistical Methods for the Behavioral Sciences. New York, Rinehart, 1954, p. 315.

4. Wolf, R. L., M. Mendlowitz, J. Pick, S. E. Gitlow, and N. Naftchi. In vitro degradation of $\mathrm{I}^{131}$ labeled angiotensin II by normotensive and hypertensive human serum. Proc. Soc. exp. Biol. (N. Y.) 1962, 109, 308.
5. Hickler, R. B., D. P. Lauler, and G. W. Thorn. Plasma angiotensinase activity in patients with hypertension and edema. J. clin. Invest. 1963, 42, 635.

6. Wolf, R. L., M. Mendlowitz, J. Pick, S. E. Gitlow, and N. Naftchi. Metabolism and distribution of $\mathrm{I}^{131}$-labeled angiotensin II. J. Lab. clin. Med. 1962, $60,150$.

7. Wood, J. E. Genetic control of neutralization of angiotensin and its relationship to essential hypertension. Circulation 1962, 25, 225.

8. Klaus, D. Untersuchungen über die Angiotensinase im Serum Gesunder und Kranker. Klin. Wschr. 1962, 40, 701.

9. Khairallah, P. A., I. H. Page, F. M. Bumpus, and R. R. Smeby. Angiotensin II; its metabolic fate. Science 1962, 138, 523.

10. Khairallah, P., F. M. Bumpus, I. H. Page, and R. R. Smeby. Angiotensinase with a high degree of specificity in plasma and red cells. Science 1963, 140, 672.

11. Kaplan, N. M., and J. Silah. The effects of angiotensin II in patients with hypertensive disease (abstract). J. clin. Invest. 1963, 42, 946.

12. Gombos, E. A., W. H. Hulet, P. Bopp, W. Goldring, D. S. Baldwin, and H. Chasis. Reactivity of renal and systemic circulations to vasoconstrictor agents in normotensive and hypertensive subjects. $\mathrm{J}$. clin. Invest. 1962, 41, 203.

13. Brod, J. Haemodynamic response to stress and its bearing on the haemodynamic basis of essential hypertension in Symposium on the Pathogenesis of Essential Hypertension. Prague, State Medical Publishing House, 1962, p. 256.

14. Brust, A. A., M. F. Reiser, and E. B. Ferris, Jr. Evaluation of neurogenic control of blood pressure in hypertension with tetraethylammonium and spinal anesthesia. J. clin. Invest. 1951, 30, 925.

15. Reiser, M. F., and E. B. Ferris, Jr. The nature of the cold pressor test and its significance in relation to neurogenic and humoral mechanisms in hypertension. J. clin. Invest. 1948, 27, 156.

16. Shapiro, A. P., and E. Krifcher. Pressor responses to noxious stimuli in hypertensive patients; effect of guanethidine sulfate and $\alpha$-methyl DOPA. To be published.

17. Bickerson, R. K., and J. P. Buckley. Evidence for a central mechanism in angiotensin induced hypertension. Proc. Soc. exp. Biol. (N. Y.) 1961, 106, 834.

18. Zimmerman, B. G. Effect of acute sympathectomy on responses to angiotensin and norepinephrine. Circulat. Res. 1962, 11, 780.

19. Page, I. H., and F. M. Bumpus. Angiotensin. Physiol. Rev. 1961, 41, 331.

20. Sharpey-Schafer, E. P., and P. J. Taylor. Absent circulatory reflexes in diabetic neuritis. Lancet 1960, 1, 559. 
21. Bárány, F. R. Abnormal vascular reactions in diabetes mellitus. Acta med. scand. (suppl.) 1955, 152, 304.

22. Stone, D. B., R. B. Talley, and J. W. Eckstein. Effects of graded doses of norepinephrine on arterial blood pressure in patients with diabetic neuropathy and orthostatic hypotension (abstract). Circulation 1961, 24, 1051.

23. Brust, A. A., and E. B. Ferris, Jr. Varying patterns of blood pressure response to autonomic blockade: implications concerning the interplay of neurogenic and humoral factors in control of vascular tone in
Proceedings of the Annual Meeting of Council on High Blood Pressure Research, American Heart Association, 1955. New York, American Heart Association, 1956, vol. 4, p. 41.

24. Page, I. H. The mosaic theory of hypertension in Essential Hypertension. An International Symposium, K. D. Bock and P. T. Cottier, Eds. Berlin, Springer, 1960, p. 1.

25. Ferris, E. B., M. F. Reiser, W. W. Stead, and A. A. Brust, Jr. Clinical and physiological observations of interrelated mechanisms in arterial hypertension. Trans. Ass. Amer. Phycns 1948, 61, 97. 